\title{
GESTÃO URBANA E INVESTIMENTO INDUSTRIAL: CONSIDERAÇÕES SOBRE O PARQUE AUTOMOTIVO DA REGIÃO METROPOLITANA DE CURITIBA
}

\author{
URBAN POLICY AND INDUSTRIAL INVESTMENT: \\ CONSIDERATIONS ON AUTOMOTIVE PARK OF CURITIBA \\ METROPOLITAN REGION
}

\author{
Hipólita Siqueira de Oliveira ${ }^{1}$ \\ ${ }^{1}$ Bolsista do CNPq, Centro de Estudos Sindicais e de Economia do Trabalho (CESIT), \\ Instituto de Economia da UNICAMP, hipolita@eco.unicamp.br
}

Recebido para publicação em: 27/11/2004

Aceito para a publicação em: 02/03/2005

\section{RESUMO}

A gestão urbana, pensada na perspectiva do estágio de desenvolvimento econômico, tem sido discutida a partir da necessidade de investimentos privados em setores estratégicos para alavancar negócios, gerar empregos e elevar a renda per capita da região. Nos anos 90, num contexto de rápidas transformações do sistema capitalista mundial e de redefinição das áreas prioritárias de localização dos investimentos industriais, mudou o foco do debate teórico sobre esta questão. Com base nas teorias do desenvolvimento endógeno, alguns estudiosos propõem novas políticas, nas quais a solução para os problemas urbanos é determinada pelos próprios recursos e condições de cada local. Dentre as novas políticas urbanas, merecem destaque o planejamento estratégico $e$ o city marketing. Ambas, com o objetivo de atrair investimentos estrangeiros e, desta forma, inserir as cidades na competição global. Embora a implementação destas novas políticas urbanas seja muito divulgada pelos governos municipais, muito pouco se discute sobre a formação de coalizões de interesses necessária para tornar as cidades "atraentes" aos olhos do capital internacional. É com o propósito de observar tal processo que o artigo analisa a vinda de empresas multinacionais do ramo automobilístico para cidades localizadas na Região Metropolitana de Curitiba - RMC.

Palavras-chave: Gestão urbana; indústria automobilística; Região Metropolitana de Curitiba.

\section{Introdução}

A gestão urbana, pensada na perspectiva do estágio de desenvolvimento econômico, tem sido discutida a partir da necessidade de investimentos privados em setores estratégicos para alavancar negócios, gerar empregos e elevar a renda per capita da região. Nos anos 90, num contexto de rápidas transformações do sistema capitalista mundial e de redefinição das áreas prioritárias de localização dos investimentos industriais, mudou o foco do debate teórico sobre esta 
questão. Com base nas teorias do desenvolvimento endógeno, estudiosos da questão têm proposto novas políticas, nas quais a solução para os problemas urbanos é determinada pelos próprios recursos e condições de cada local. Dentre as novas políticas urbanas, merecem destaque o planejamento estratégico e o city marketing. Ambas, com o objetivo de atrair investimentos internacionais e, desta forma, inserir as cidades na competição global.

As análises do desenvolvimento endógeno têm seu início com base nas experiências locais exitosas da Terceira Itália e do Vale do Silício. Nestes estudos, são estabelecidas as tipologias de Distritos Industriais, complexos territoriais high tech, tecnópoles, pólos de serviços industriais, etc., em grande parte, fundamentados no modelo da "especialização flexível” de Piore; Sabel (1984). De acordo com este modelo, as empresas precisam se reorganizar para que possam ser capazes de responder de maneira rápida e flexível às mudanças nas condições de mercado desencadeadas pela crise da produção em massa. Isto, por sua vez, implica numa nova organização territorial da produção, onde as regiões são vistas como uma unidade de produção integrada. Daí o reconhecimento da importância dos novos espaços industriais para o crescimento endógeno das economias regionais.

Dentre alguns dos principais autores do desenvolvimento local estão os italianos (BECATTINI; GAROFOLIi) e os californianos (SCOTT; STORPER). Para os primeiros, a configuração territorial do novo padrão de acumulação é o Distrito Industrial Marshalliano ${ }^{1}$. A dinâmica desta organização territorial produtiva é determinada mais por relações extra-mercado presentes na comunidade local do que por relações mercantis. Ou seja, a interação coletiva entre os agentes locais (comunidade, empresas e instituições locais), com base na cooperação e na concorrência, é que determina os rumos do crescimento local. A flexibilidade desta organização é garantida pela presença de uma rede de pequenas e médias empresas especializadas, dotadas de grande capacidade de inovação.

Já os autores californianos expandem a noção de distrito industrial para as metrópoles. Estas, além de possuírem economias de aglomeração que são fontes essenciais para o crescimento do local, viabilizam a constituição de vários distritos industriais. Ao contrário dos autores italianos, a dinâmica do crescimento não é dada pela capacidade de inovação das pequenas e médias empresas, mas sim, pela inovação que é gerada dentro das grandes empresas.

Uma das críticas feitas a estes autores está relacionada ao fato de que, apesar de reconhecerem as especificidades históricas das experiências locais, estes transpõem a lógica da "especialização flexível" para todos os tipos de aglomerações espaciais produtivas (AMIN; ROBINS, 1994). Por outro lado, alguns autores atribuem às pequenas e médias empresas um papel central na dinâmica regional,

\footnotetext{
${ }^{1}$ Para Becattini, o Distrito Industrial Marshalliano é “... una entidad socioterritorial caracterizada por la presencia activa de una comunidad de personas y de una población de empresas en un espacio geográfico e histórico dado.” (BENKO; LIPIETZ, 1994, p. 40)
} 
num momento em que se verifica o fortalecimento das grandes corporações transnacionais, com o aumento das fusões e aquisições no mundo inteiro (MARTINELLI; SCHOENBERGER, 1994). Além disso, nestas análises não são consideradas as dificuldades de reprodução dos casos exitosos em outros contextos, bem como alguns condicionantes externos e suas implicações sobre o local (os efeitos das políticas macroeconômicas, o aumento da centralização do capital, o capital financeiro, etc).

Apesar das diferenças entre os diversos autores do desenvolvimento endógeno, o ponto em comum a ser enfatizado está na proposição de que a solução para os problemas de cada local deve ser buscada em suas próprias condições e recursos internos. As gestões urbanas cada vez mais estão sendo influenciadas por estas visões e vem ressaltando a necessidade de fomentar o dinamismo e as vantagens competitivas de cada cidade. Dentre estas novas políticas urbanas, podemos citar os grandes projetos de revitalização de centros e áreas degradadas, os planos estratégicos, as políticas de city marketing, etc. Todas, com o objetivo de tornar as cidades atrativas ao capital global e, desta forma, inserir a localidade no "comércio internacional de cidades". Com ênfase no papel das cidades como "motor do crescimento mundial", a justificativa para a implementação de tais políticas é dada pelo potencial de geração de renda e emprego dos investimentos atraídos a partir destas iniciativas.

Embora a implementação destas novas políticas urbanas seja muito divulgada pelos governos locais, muito pouco se discute sobre a formação de coalizões de interesses necessária para tornar as cidades "atraentes" aos olhos do capital internacional. É com o objetivo de observar tal processo que analisaremos a vinda de empresas internacionais do ramo automobilístico para cidades localizadas na Região Metropolitana de Curitiba - RMC. Antes de analisar determinantes da instalação de empresas automobilísticas na RMC, torna-se necessário verificar quais os instrumentos das políticas urbanas recentes e o processo global de reestruturação produtiva do setor automobilístico, os interesses das grandes empresas e o contexto macroeconômico nacional no qual estas montadoras se instalaram no Brasil.

\section{As propostas e os instrumentos das novas políticas urbanas}

Segundo as proposições políticas das agências multilaterais de fomento e de alguns consultores internacionais (BORJA; CASTELLS, 1997) as cidades, além de oferecer uma base histórica e cultural para a integração dos indivíduos, devem estar em condições de atrair e promover a competitividade do capital internacional. Com isso, enfatiza-se o poder de atuação das políticas locais em diversos contextos sócio-territoriais e a implementação de uma gestão urbana capaz de tornar possível a inserção das cidades no mercado internacional. A parceria público-privada é essencial para a implementação das políticas daí derivadas. 
Neste contexto, o city marketing tornou-se um importante instrumento das novas políticas urbanas. Serve de apoio às políticas de atração de investimentos, sendo muito utilizado pelas gestões urbanas e estaduais no Brasil e no mundo. Atualmente, assiste-se a uma onda de propagandas de municípios/Estados em todos os meios de comunicação (internet, rádio, TV, revistas especializadas ou não, etc.), de slogans do tipo "Eu amo minha cidade" e imagens-síntese como "A Capital da Tecnologia". Porém, esta estratégia de transformar uma determinada cidade numa localidade "vantajosa" a investimentos externos não é um fenômeno novo. Historicamente, vários governos com base em determinadas coalizões produziram espaços "atraentes” ao capital. A novidade está na transformação do espaço (cidade) em mercadoria internacional. Dentro desta lógica, o city marketing é muito importante para apresentar e promover as cidades no mercado externo.

Contudo, segundo Vainer (2000) a cidade é uma mercadoria muito complexa. O que é vendido através de artifícios como o city marketing são aqueles atributos específicos da cidade que representam "insumos" ao capital internacional, como: parques industriais e tecnológicos, centros de convenção, qualidade de vida, segurança, etc. A seleção de determinadas cidades como mercadoria é feita pelo mercado externo e, desta forma, a cidade se torna "... uma mercadoria de luxo, destinada a um grupo de elite de potenciais compradores: capital internacional, visitantes e usuários solváveis." (VAINER, 2000, p. 3).

A produção de imagens-síntese por meio do city marketing, de acordo com Sanchéz (1999), não têm o objetivo de informar sobre a cidade, mas sim, de idealizá-la. Nesta perspectiva, são emblemáticos os exemplos, identificados por esta autora, na cidade de Curitiba: Cidade-Modelo e Capital Humana (anos 70); Capital da Qualidade de Vida (anos 80); Capital Ecológica (anos 90). Com a fabricação destas imagens, Curitiba se tornou uma das cidades brasileiras mais conhecidas internacionalmente. Porém, ressalta Sanchéz, este é “um campo de investimentos simbólicos que necessitam ser constantemente disputados e renovados”. Neste sentido, nos anos 90, houve uma renovação da imagem-síntese de Curitiba para atrair as montadoras de automóveis. A imagem de "Capital Ecológica" foi incorporada pelo slogan de "Capital Tecnológica", assumindo assim um viés industrial no city marketing.

Embora este tipo de política tenha sido um fator de grande eficácia, não foi exclusivamente pela implementação desta que a RMC conseguiu se tornar uma localidade vantajosa e desta forma, atrair investimentos de grandes empresas do ramo automobilístico. No caso de Curitiba, ao contrário do que afirmam os "localistas", a vinda destas empresas não dependeu exclusivamente dos "fatores locais" e da gestão urbana implementada. Para tal, foram necessárias certas “... racionalidades nacionais que traduzem o País como norma, seja na forma de incentivos fiscais, 
flexibilidades regulatórias, liberalização comercial, suporte técnico e infra-estrutural, isenções, possibilidade de parcerias...” (SANCHÉZ, 1997, p.175).

\section{As mudanças organizacionais do setor automobilístico}

Nas últimas décadas, em função da maturidade e da saturação dos mercados dos países desenvolvidos, as grandes empresas da indústria automobilística implementaram um processo de reestruturação produtiva em nível mundial. Com o acirramento da concorrência pelos mercados dos países emergentes, estas empresas intensificaram suas estratégias de internacionalização da produção baseadas no esquema de global sourcing. Além da instalação de fábricas em áreas próximas aos mercados emergentes, a principal medida neste sentido foi a reorganização da produção e da rede de fornecedores com base no sistema modular.

No Brasil, a reorganização da produção automobilística se iniciou na década de 90 . As estratégias das filiais instaladas no País e das novas empresas atraídas se voltaram para a expansão do mercado interno e às possibilidades de integração ao Mercosul. Além das políticas de liberalização comercial e dos planos de estabilização do Brasil e dos países do Mercosul, também foram importantes as políticas nacionais específicas para o setor automobilístico. Com destaque para o Regime Automotivo do Brasil que, apesar da falta de políticas industriais de âmbito nacional nos anos 90, foi uma das poucas medidas do Governo Federal adotadas neste sentido ${ }^{2}$. A atração de novos investimentos; o estímulo à exportação de automóveis, através de regimes especiais de importação; e a consolidação do Brasil como o principal produtor do Mercosul eram os principais objetivos deste regime.

Nos primeiros anos da década de 90, a abertura comercial e a diminuição gradual das tarifas de importação resultaram num aumento da concorrência com os carros importados. A reação das empresas à esta pressão concorrencial ocorreu de maneira "defensiva", com base na redução do número de trabalhadores; terceirização de atividades; renovação de produtos, atualização tecnológica e importação de componentes. Entre 1994-96, diante da intensificação da redução das tarifas de importação, as automobilísticas aumentaram as importações de carros e componentes para atender à expansão do mercado interno e do MERCOSUL. Foi somente no final de 1996 que as automobilísticas definiram suas estratégias para estes mercados. Com base nestas definições, ocorreu um novo ciclo de investimentos sob a forma de modernização e ampliação da capacidade produtiva de plantas automobilísticas já existentes e de instalação de novas plantas no Brasil.

A partir daí, tanto as novas unidades como as fábricas já existentes no País começaram a produzir com base num modelo de organização da produção diferente daquele fundamentado na

\footnotetext{
${ }^{2}$ Ver (LAPLANE, et al 2001).
} 
verticalização de atividades. Neste modelo, as montadoras se restringem à produção de componentes considerados estratégicos e focalizam suas atividades na montagem e distribuição de produtos finais. A fabricação dos componentes de maior complexidade tecnológica, e até mesmo de partes dos veículos, é transferida para seus fornecedores principais, através das políticas de follow sourcing e single sourcing ${ }^{3}$.

Segundo Santos; Pinhão (2000), o resultado destas mudanças organizacionais foi a intensificação das fusões e aquisições no segmento de autopeças, aumentando a importância de um conjunto de empresas que atuam em escala internacional. Por outro lado, houve um aumento da concentração das atividades de maior complexidade tecnológica ( $\mathrm{P} \& \mathrm{D}$, design, etc.) nos principais centros de desenvolvimento. Isto, por sua vez, implicou numa diminuição das atividades de adaptação realizadas nos países menos desenvolvidos. No Brasil, os impactos da reorganização da rede de fornecedores das automobilísticas sobre o segmento de autopeças foram significativos. Além do aumento das importações de autopeças, as empresas nacionais sofreram pressões referentes à capacitação tecnológica, para que pudessem participar do processo de seleção de fornecedores promovido pelas montadoras. Porém, estes autores ressaltam que as principais conseqüências destas mudanças foram a significativa incorporação de empresas nacionais por empresas estrangeiras; a entrada de grandes fornecedores mundiais; e o fortalecimento daqueles que já estavam presentes no País. As poucas empresas nacionais "escolhidas" passaram a atuar sob a forma de joint ventures, sendo que a maioria se restringe aos segmentos de menor complexidade tecnológica ${ }^{4}$.

Em termos regionais, a modernização tecnológica das fábricas de automóveis e os efeitos negativos da reorganização da rede de fornecedores de autopeças causaram desemprego na região do ABCD paulista ${ }^{5}$. Por outro lado, embora a maior parte dos investimentos totais do setor automobilístico tenha se destinado ao Estado de São Paulo, os investimentos em novas plantas automobilísticas não ocorreram nesta região. O Estado do Paraná foi responsável por 33\% dos investimentos em novas plantas na segunda metade dos anos 90.

Participação dos Estados nos Investimentos do Setor Automobilístico entre 1996-2000, em \%

\begin{tabular}{lcc}
\hline \multicolumn{1}{c}{ Estados } & Investimentos Totais & Investimento em novas plantas \\
\hline São Paulo & 45 & 8 \\
Minas Gerais & 22 & 19 \\
Paraná & 16 & 33 \\
Bahia & 8 & 18 \\
Rio de Janeiro & 5 & 12 \\
Rio Grande do Sul & 4 & 10 \\
\hline
\end{tabular}

\footnotetext{
${ }^{3}$ Estas práticas consistem na escolha de fornecedores mundiais que acompanham as montadoras nos países em que se instalam e de fornecedores únicos para determinadas peças e componentes. Estes fornecedores-chave se localizam em área próxima ou até mesmo no interior das plantas de montagem dos veículos. Ver (SANTOS; PINHÃO, 2000).

${ }^{4}$ (SANTOS; PINHÃO, 2000) destacam o fato de que no Brasil os segmentos de maior complexidade tecnológica já eram dominados por empresas internacionais, mais especificamente, pelas montadoras.

${ }^{5}$ Região formada pelos municípios de Santo André, São Bernardo do Campo, São Caetano, Diadema, Mauá, Ribeirão Pires e Rio Grande da Serra.
} 


\begin{tabular}{ccc}
\hline Total & 100 & 100 \\
\hline
\end{tabular}

Fonte: SANTOS; PINHÃO (2000).

A instalação de novas plantas no interior do Estado de São Paulo e em outros Estados deu início à formação de novos pólos automobilísticos no País, em detrimento do parque automobilístico concentrado na região do $\mathrm{ABC}$ paulista ${ }^{6}$. Mas, apesar deste deslocamento de investimentos, com exceção da fábrica da Bahia, a produção automobilística continuou restrita nos limites da região CentroSul. Os investimentos mais significativos se destinaram a Estados onde já estavam presentes algumas fábricas automobilísticas (São Paulo, Minas Gerais, Paraná e Rio Grande do Sul). Além disso, os novos investimentos realizados fora da Região Sudeste se concentraram nos espaços de maior dinamismo relativo aumentando assim, as desigualdades intra-regionais destes Estados (Camaçari na Bahia, Região Metropolitana de Curitiba e Região Metropolitana de Porto Alegre).

As novas fábricas automobilísticas trouxeram para os Estados em que se instalaram alguns de seus fornecedores principais que já atuavam com estas empresas em outros países. Entretanto, devido à instalação recente destas montadoras nos novos pólos grande parte do fornecimento de autopeças ainda é proveniente do Estado de São Paulo. À exceção do pólo de Minas Gerais que, através de mecanismos estaduais de política industrial, vem implementando desde os anos 80 o projeto de "mineirização" dos fornecedores de autopeças. Inicialmente, este programa estimulou algumas empresas locais e atraiu empresas de São Paulo. Mas, em virtude das mudanças estratégicas da Fiat, fornecedores mundiais também foram atraídos para este pólo ${ }^{7}$.

No quadro a seguir pode ser verificada a distribuição regional dos investimentos em novas plantas do setor automobilístico entre 1996 e 2002.

Distribuição Regional das Novas Plantas Automobilísticas (1996/2001)

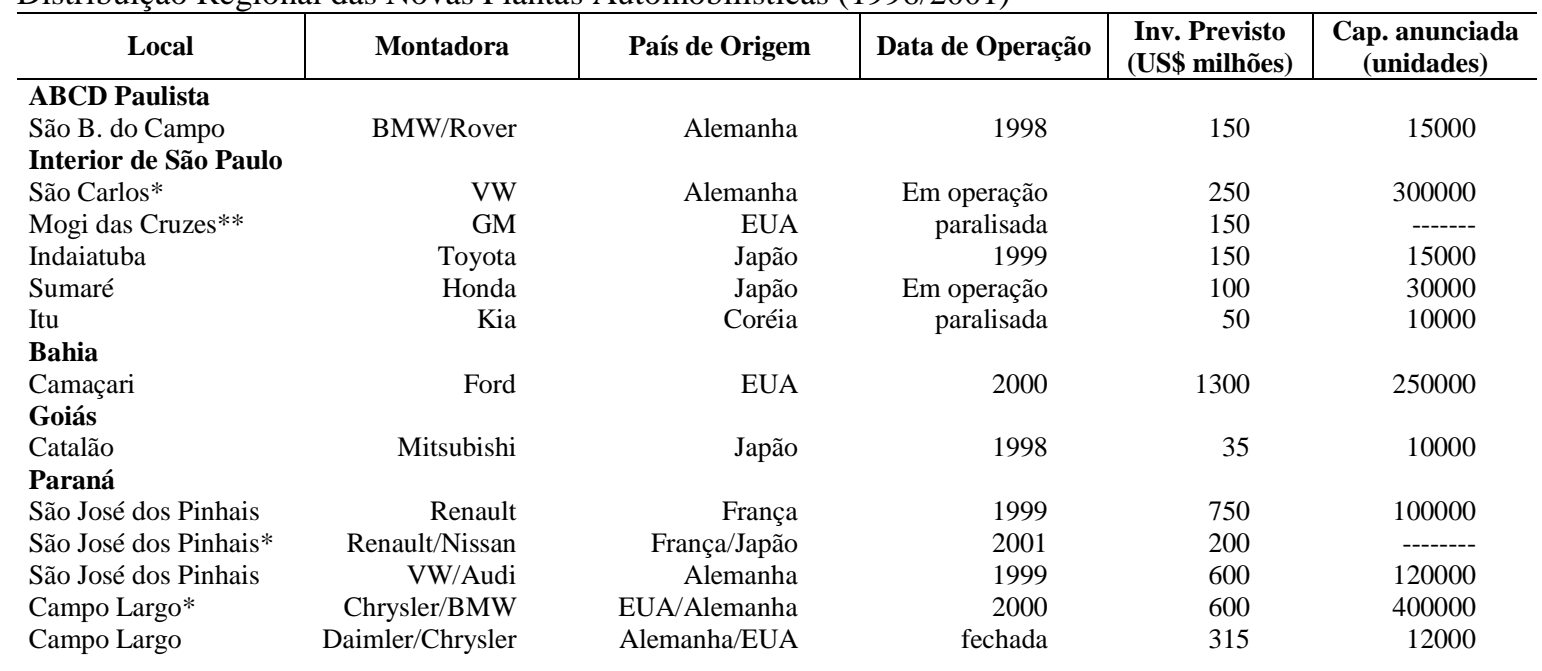

${ }^{6}$ Desde a sua implantação no Brasil, a indústria automobilística esteve concentrada na Região Metropolitana de São Paulo, mais precisamente, no ABC paulista. Neste período, filiais de empresas multinacionais como, Ford, Volkswagen, Toyota, Mercedes Benz, Scania, GM e Ford aí se instalaram. Nos anos 80, ocorreu uma desconcentração da produção automobilística no sentido do interior do Estado de São Paulo e de outras regiões brasileiras. A VW e a Ford se instalam em Taubaté e a GM em São José dos Campos. A FIAT se instalou em Minas Gerais, a Volvo no Paraná e a Agrale no Rio Grande do Sul (PACHECO, 1998).

${ }^{7}$ Ver (LEMOS, 2000). 


\begin{tabular}{|c|c|c|c|c|c|}
\hline \multicolumn{6}{|l|}{ Minas Gerais } \\
\hline Juiz de Fora & Daimler & Alemanha & 1999 & 820 & 70000 \\
\hline Sete Lagoas & Iveco & Itália & 1998 & 250 & 20000 \\
\hline \multicolumn{6}{|l|}{ Rio de Janeiro } \\
\hline Porto Real & Peugeot & França & 2000 & 600 & 100000 \\
\hline Resende & VW & Alemanha & 1996 & 250 & 50000 \\
\hline Caxias do Sul & Navistar & EUA & 1998 & 50 & 5000 \\
\hline
\end{tabular}

Fonte: (ARBIX, 2000). *Produção de Motores; ** Produção de Autopeças.

Dentre os fatores que contribuíram para a instalação destas plantas fora da região do ABCD paulista foram mencionados pelas empresas: a posição geográfica estratégica dos estados da Região Sul em relação aos países do Mercosul; a relação capital-trabalho menos "conflituosa" e os menores custos salariais, em comparação à região do ABCD paulista; as melhorias na infraestrutura de escoamento da produção; e os incentivos fiscais e financeiros. Contudo, a acirrada disputa entre as diversas Unidades da Federação (guerra fiscal) para atrair tais investimentos, através da concessão de isenções/incentivos fiscais e financeiros, é considerada como o fator determinante deste deslocamento de investimentos ${ }^{8}$. Além destes benefícios, as montadoras também contaram com financiamentos do BNDES e com benefícios concedidos pelos municípios nos quais se instalaram, que vão desde a doação de terrenos a isenções de impostos, taxas e contribuições.

O setor automobilístico merece destaque pela sua capacidade de gerar efeitos em termos de emprego, renda, atração de fornecedores, etc. Contudo, vale ressaltar que, em virtude da reestruturação produtiva do setor descrita anteriormente, houve uma diminuição destes links intersetoriais e, conseqüentemente, dos potenciais impactos sobre emprego e renda. Acrescente-se a isto, a elevada capacidade produtiva apresentada pelo setor automobilístico, a redução das vendas de veículos para o mercado interno e a crise da Argentina, principal mercado importador de veículos do Brasil, que vem resultando em demissões de trabalhadores e na paralisação de montadoras em todo o País. Neste cenário, os desdobramentos dos novos investimentos sobre o dinamismo das regiões em que se instalaram poderão ser bem menores do que os esperados.

\section{Empresas automobilísticas no estado do Paraná}

O Estado do Paraná mereceu destaque nesta nova onda de investimentos por ter recebido a maior parte das novas plantas industriais, sendo que as empresas que aí se localizaram ainda não produziam no Brasil. Também foram atraídos alguns investimentos de empresas do segmento de autopeças que são fornecedoras destas empresas em outros países. Estes investimentos se

\footnotetext{
${ }^{8}$ Para maiores detalhes sobre os incentivos fiscais e financeiros concedidos às empresas automobilísticas no Brasil durante os anos 90 ver (ALVES, 2001).
} 
concentraram na RMC, onde já estava presente uma unidade de produção de caminhões e ônibus da Volvo.

O pólo automotivo instalado na RMC é destacado por sua modernidade tecnológica. As unidades das montadoras são equipadas com máquinas e robôs de última geração, as tintas utilizam água como solvente e as máquinas de limpeza utilizam "penas de ema" para reter as impurezas. A produção de automóveis está organizada com base no sistema modular, onde as montadoras focaram suas operações nas atividades de pintura, montagem e estamparia pesada e os fornecedores de primeira linha, grande parte do mesmo país de origem das montadoras, estão localizados em área próxima à da fábrica. No início, a estratégia da instalação destas plantas se deu com base na possibilidade de integração do mercado brasileiro com o mercado dos países do Mercosul, especialmente da Argentina. De modo que, as linhas de produção destas empresas compartilhassem componentes de fornecedores em comum, estes com unidades produtivas tanto no Brasil como na Argentina. Porém, com a crise da Argentina, vários destes fornecedores de autopeças transferiram suas unidades de produção para o Brasil.

Dentre os fatores considerados como decisivos para a instalação destas empresas no Estado do Paraná, estão:

- A posição geográfica estratégica com relação ao Mercosul e a São Paulo;

- A proximidade geográfica com o pólo automobilístico de Córdoba na Argentina;

- Financiamentos concedidos pelo Fundo de Desenvolvimento Econômico (FDE) do Estado do Paraná;

- Isenção e incentivos fiscais e tributários;

- Doação de terreno para instalação das plantas;

- Melhoria das infra-estruturas de escoamento da produção;

- Mão de Obra qualificada e mais “dócil” em comparação à do ABC paulista.

As estratégias de city marketing por parte do Estado do Paraná e, em especial, da cidade de Curitiba, foram de grande eficácia para a atração destas montadoras. Visto que, Curitiba ao servir como "porta de entrada" para a instalação destes investimentos em sua região metropolitana, se beneficiou com a abertura de três grandes shopping-centers, de faculdades, de várias escolas de línguas, de espaços de lazer, cultura e outros.

Um exame minucioso do Protocolo de Acordo realizado entre a maior das empresas que se instalou neste novo pólo automobilístico (Renault) e o Estado do Paraná mostra que este tipo de gestão urbana não foi o principal condicionante para a instalação destas montadoras na RMC. Neste protocolo, está posto que a instalação desta empresa elevaria a oferta de empregos diretos e indiretos e contribuiria para o aumento das exportações do Estado do Paraná. Desta forma, em função do grande volume de recursos necessários para a realização dos investimentos, a Renault 
solicita o apoio do Governo Federal, do Governo do Estado do Paraná e do Município de São José dos Pinhais, os quais aceitaram, de maneira favorável, tal pedido.

No item das responsabilidades do Estado do Paraná, os benefícios tributários se relacionaram a desoneração e diferimento do ICMS incidente sobre uma série de itens adquiridos em outros Estados do País, no exterior ou no próprio Paraná. Todos estes incentivos fiscais também foram concedidos para os fornecedores desta empresa. O Estado do Paraná, através do FDE, também se comprometeu a conceder financiamento para a atividade comercial e para o investimento da Renault. Com relação ao financiamento do investimento este seria liberado em parcelas mensais pelo prazo de dez anos, sem juros, comissões e correções monetárias. Com isso, o FDE passou a deter participação de $40 \%$ do capital da Renault do Brasil em ações nominativas preferenciais sem direito a voto (denominadas “Ações B”).

Com relação ao Município de São José dos Pinhais, coube a este: isenção do IPTU, do ISS, da Contribuição de Melhorias, da Taxa Municipal de Licença de Localização e Funcionamento e quaisquer outras taxas municipais, pelo prazo de 10 anos. Neste caso, todas as isenções também foram estendidas às subsidiárias e aos fornecedores da empresa que viessem se instalar neste município.

O Estado do Paraná e o Município de São José dos Pinhais ficaram responsáveis pela doação de um terreno para a constituição do parque automotivo da Renault. Este terreno deveria ter uma área não inferior a $2.500 .000 \mathrm{~m}^{2}$ e ser livre de pessoas, coisas, construções, impostos e taxas, inclusive os incidentes sobre a transferência da propriedade. Deveria ser reservada ainda, uma área de $500.000 \mathrm{~m}^{2}$ contígua ao terreno para futuras expansões da empresa, pelo prazo de 10 anos. Além disso, a realização das obras de organização, urbanismo, infra-estrutura e abastecimento do referido parque também ficaram a cargo deste Município e do Estado.

Em contrapartida, a Renault se comprometeu apenas em: estabelecer sua sede social no Município de São José dos Pinhais; empreender a realização do investimento; fazer as modificações estatutárias necessárias para que o FDE participasse do capital da empresa; respeitar a legislação ambiental; e transferir à Renault do Brasil sua tecnologia, seus conhecimentos e assistência técnica.

Tendo em vista os benefícios concedidos pelo Estado do Paraná e por São José dos Pinhais e a contrapartida devida pela empresa, percebe-se que estes ofereceram muito mais do que “qualidade de vida de Primeiro Mundo" para a instalação destes investimentos na RMC.

Sob estas condições, esta empresa, começou a produzir os veículos da linha Clio em 1999 no Município de São José dos Pinhais. E, em 2003, também inaugurou uma planta industrial de utilitários em parceria com a Nissan, neste mesmo município. A área em que a Renault instalou-se é 
estratégica ${ }^{9}$, com fácil acesso ao Porto de Paranaguá, ao Aeroporto Internacional Afonso Pena (São José dos Pinhais), à Curitiba e à rodovia que liga o Paraná aos demais Estados da Região Sul; à São Paulo; e aos países integrantes do Mercosul.

Além da Renault e da Nissan, outras plantas automobilísticas se instalaram no Paraná, Volkswagen-Audi em São José dos Pinhais; e Chrysler, em Campo Largo. Com estes investimentos, a participação relativa do Paraná no Valor da Transformação Industrial (VTI) nacional da fabricação e montagem de veículos automotores aumentou de 3,5\% para 8,6\% entre $1985-2000^{10}$. No VTI estadual o aumento foi $4,1 \%$ para $11,5 \%$. Segundo dados da RAIS, o aumento do emprego neste setor na Região Metropolitana de Curitiba foi de 4.392 para 17.424 entre 19962000.

A instalação das montadoras gerou efeitos positivos em termos da geração de emprego e de ativação do comércio nas cidades em que se instalaram, bem como aumentou o número de escolas de línguas, faculdades de administração, cursos pós-graduação em marketing, logística, entre outras atividades de serviços.

Por outro lado, a Chrysler instalada em Campo Largo fechou sua fábrica em 2000. Esta decisão fez parte do programa de reestruturação do grupo Daimler-Chrysler, em reação à redução das vendas do modelo produzido na fábrica do Paraná (caminonete Dakota). A produção desta empresa foi de aproximadamente 4 mil unidades, sendo que a capacidade produtiva instalada era de 12 mil unidades por ano. Com o seu fechamento, 250 funcionários da Chrysler foram demitidos, com efeitos negativos sobre o comércio de Campo Largo. As demissões se estenderam a seus fornecedores (Dana, Detroit Diesel e Lear) que se instalaram no Paraná exclusivamente para atender esta empresa.

A duração das atividades da fábrica de Campo Largo foi de apenas três anos. A justificativa do grupo Daimler-Chrysler para a interrupção destas atividades foi a de que "o mercado não se comportou conforme o previsto", uma vez que, no período em que a empresa decidiu se instalar no Brasil, as previsões sobre a automobilística eram muito otimistas.

Por causa da diminuição das vendas para o mercado interno e para o Mercosul, as montadoras de modo geral têm recorrido ao Governo Federal para reduzir o IPI sobre os carros, agilizar acordos de intercâmbio comercial visando a exportação para outros países, etc. A Renault decidiu investir nas exportações de motores para o México e Europa. As mudanças na política cambial também contribuem para estas decisões, pois a desvalorização cambial reduz os custos de produção destas empresas no Brasil, em relação aos custos da Europa e da América Latina.

\footnotetext{
${ }^{9}$ Vale ressaltar que esta era uma área de preservação ambiental.

${ }^{10}$ Dados da Pesquisa Industrial Anual (PIA) do IBGE.
} 


\section{Considerações finais}

Entende-se que esta estratégia foi de grande eficácia, porém, não foi o principal condicionante para a execução de tal empreendimento. A vinda destas empresas para a Região Metropolitana de Curitiba (RMC) foi apoiada pela atuação de outras instâncias de governo (federal e estadual). Além disso, a estabilidade do ambiente macroeconômico, a expansão do mercado interno, a integração comercial entre os países do Mercosul e as políticas específicas para o setor automobilístico foram essenciais para a instalação destas plantas automobilísticas no Brasil. Por outro lado, a vinda destas empresas para o País também é consequiência das estratégias de internacionalização das grandes empresas automobilísticas. Desta forma, ao contrário do que vem sendo proposto pelas novas políticas urbanas, o estabelecimento das condições necessárias para a atração de grandes investimentos para uma determinada localidade não depende exclusivamente da gestão "empreendedora” do poder local.

Por fim, guardadas as especificidades da indústria automobilística com relação à geração de dinamismo local, entende-se que, pelo menos no contexto territorial brasileiro, ao contrário do que propõe as novas políticas urbanas, a "solução" para a crise de cada cidade não está dada por suas próprias condições e recursos locais. Para viabilizar a instalação de empresas automobilísticas na RMC exigiu-se esforços de outras escalas de governo (federal e estadual), assim como também certas regularidades do ambiente macroeconômico e de políticas industriais específicas como o Regime Automotivo foram essenciais para tal empreendimento.

Isto, por sua vez, confirma a necessidade de considerar os limites do poder local. Torna-se necessário, avaliar em que medida os governos municipais conseguem reverter uma situação de crise, apesar dos constrangimentos a que estão submetidos. Em outras palavras, qual a capacidade efetiva dos governos municipais de resolver problemas causados por determinações várias que extrapolam a sua esfera de atuação como, por exemplo, a crise estrutural do emprego. Neste sentido, em conformidade com Vainer (2001) é preciso perguntar "O que pode o poder local?" e, para isso é preciso compreender que:

“... a estrutura social, econômica e política, que opera na interação entre as escalas nacional e internacional, é o principal determinante das condições de vida das classes subalternas em nossa sociedade, e somente mudanças estruturais profundas serão capazes de abrir possibilidades para uma reversão do quadro de desigualdades e de miséria social." (VAINER, 2001, p. 15).

Assim como ressaltado em Sanchéz (1997), o local em que se instalam as fábricas de veículos torna-se mais específico, com limitadas funções, e desta forma, mais rígido pois, está, cada vez mais, subordinado às estratégias das grandes corporações internacionais. Vale lembrar que no global sourcing a produção se descentraliza, mas isto não implica numa descentralização do poder 
de comando. Desta forma, os espaços estão sobredeterminados por objetivos e ações de esquemas de produção de âmbito mundial, que extrapolam os limites regionais. Além disso, uma vez que o dinamismo local e os empregos gerados foram menores do que os esperados, a relação custobenefício dos empreendimentos automobilísticos no Paraná não foi muito favorável. Sobrepõe-se a isto o fato de que o volume de investimentos públicos destinados à vinda das montadoras para esta região poderiam ter sido destinado para projetos na área social.

\begin{abstract}
Urban policy, taken from the perspective of economic development, has been discussed under the necessity of private investments in strategical sectors to stimulate businesses, generate jobs and raise the region's per capita income. In the 90's, on a context of world-wide capitalist system transformations and industrial investment areas redefinition, the focus of the theoretical debate about this question changed. Based on endogenous development theories, some scholars suggest new policies, in which the solution for urban problems is determined by each locality's own resources and conditions. Amongst these policies, strategical planning and city marketing deserve prominence. Both intend to attract foreign investments, thus inserting the cities in the global competition. Although their implementation is very divulged by municipal governments, not much is discussed about the formation of the interest coalitions necessary make the cities "attractive" to the international capital. Intending to observe such process, this article analyzes the attraction of multinational automotive companies to cities located in Curitiba Metropolitan Region.
\end{abstract}

Key words: Urban policy, automotive industry, Curitiba Metropolitan Region

\title{
6. Referências
}

ALVES, Maria A. Guerra fiscal e finanças federativas no Brasil: o caso do setor automobilístico. 2001. Dissertação (Mestrado) - Instituto de Economia, UNICAMP, Campinas, 2001.

AMIN, A.; ROBINS, K. El Retorno de Las Economías Regionales. Geografia Mítica de la Acumulación Flexible. In: BENKO, G.; LIPIETZ, A. (Orgs). Las Regiones que Ganan. Valencia : Alfons el Magànim, 1994.

ARBIX, G. Política Industrial e o Laissez-Faire na Guerra Fiscal. In: RATTNER, H. (Org.). Brasil no Limiar do Século XXI. São Paulo: EDUSP, 2000.

BENKO, G.; LIPIETZ, A. (Orgs). Las Regiones que Ganan. Valencia : Alfons el Magànim, 1994.

BORJA, J.; CASTELLS, M. Local y Global: la gestión de las ciudades en la era de la información. Madrid : Grupo Santillana de Ediciones, 1997.

FERNANDES, Ana Cristina. Da reestruturação corporativa à competição entre cidades: lições urbanas sobre os ajustes de interesses globais e locais no capitalismo contemporâneo. Espaço \& Debates, São Paulo, n. 41, 2001.

GAZETA MERCANTIL. Balanço Anual. Paraná. [Vários números].

GOVERnO DO ESTAdo DO PARANÁ. Protocolo de Acordo Renault-Estado do Paraná. Disponível em: <http://www.senado.gov.br/web/senador/requiao/cpiado.htm>. Acesso em: 24 maio 2004.

LAPLANE, M. et al. Empresas transnacionais no Brasil nos anos 90: fatores de atração, estratégias e impactos. In: CHUDNOVSKY, D. (Coord.). El boom de inversión extranjera directa en el MERCOSUR. Buenos Aires: Siglo XXI de Argentina Editors, 2001.

LEMOS, M. B. et al. O Arranjo Produtivo da Rede Fiat de Fornecedores. In: CASSIOLATO, J. E.; LASTRES, H. M. M. (Coords.). Arranjo e sistemas produtivos locais e as novas políticas de desenvolvimento industrial e tecnológico. Rio de Janeiro: IE/UFRJ, 2001. (Nota técnica; 15). 
MARTINELLI, F.; SCHOENBERGER, E. Los oligopolios están bien, gracias. Elementos de reflexión sobre la acumulación flexible. In: BENKO, G.; LIPIETZ, A. (Orgs). Las regiones que ganan. Valencia : Alfons el Magànim, 1994.

PACHECO, C. A. Fragmentação da nação. Campinas: IE/UNICAMP, 1998.

PIORE, M. J.; SABEL, C. F. The second industrial divide: possibilities for prosperity. New York : Basic Books, 1984.

SANCHÉZ, Fernanda. Reorganização do espaço metropolitano e marketing territorial: o caso da grande Curitiba. In: ENCONTRO NACIONAL DA ANPUR, 7., 1997, Recife. Anais... Recife, 1997.

Políticas urbanas em renovação. Uma leitura crítica dos modelos emergentes. Estudos Urbanos e Regionais, São Paulo, n. 1, maio 1999.

Cidades reinventadas para um mercado mundial: Estratégias trans-escalares nas políticas urbanas. In: ENCONTRO NACIONAL DA ANPUR, 9., 2001, Rio de Janeiro. Anais... Rio de Janeiro: IPPUR/UFRJ, 2001.

SANTOS, A. M. M. M.; PINHÃO, C. M. A. Investimentos do complexo automotivo: atuação do BNDES. BNDES Setorial, Rio de Janeiro, n. 12, set. 2000.

VAINER, Carlos B. As escalas do poder e o poder das escalas: o que pode o poder local. In: ENCONTRO NACIONAL DA ANPUR, 9., 2001, Rio de Janeiro. Anais... Rio de Janeiro: IPPUR/UFRJ, 2001.

Pátria, empresa e mercadoria. Notas sobre a estratégia discursiva do planejamento estratégico urbano. In: ARANTES, O.; VAINER, C. B.; MARICATO, E. A cidade do pensamento único: desmanchando consensos. Petrópolis: Vozes, 2000. 